\title{
Telas urbanas: do néon às projeções efêmeras
}

\author{
Luciana Moherdaui' \\ https://orcid.org/0000-0003-2372-0046 \\ I - FAU-USP \\ São Paulo (SP), Brasil
}

Resumo: O objetivo deste artigo é discutir quais implicações legais serão enfrentadas quando as cidades informacionais, estruturadas no espaço de fluxo, principal base da sociedade em rede, forem ocupadas por interfaces de projeções efêmeras reproduzidas por meio de dispositivos móveis. Nesse contexto, fundamentarão essa reflexão o reexame da Lei Cidade Limpa e as noções de espaços liso, sem fronteiras, estriado, delimitado, e de Disneyworld, na qual a ordem do mundo é disnéica, para além do imaginário, em que o real se torna um parque de atrações, uma tela total.

Palavras-chave: internet; interface; cidade informacional; Disneyworld.

Abstract: Urbans secreens: from neon to ephemeral projections - The purpose of this article is to discuss which legal implications will be confronted when the informational cities, structured in the flow space, a main feature of the network society, become occupied by digital interfaces via mobile devices. In this context, this reflexion will be substantiated by a review of the Cidade Limpa law and the notions of smooth spaces, without borders, striated spaces, delimited, and of the Disneyworld, in which the order of the world is disneyc, beyond the imaginary, in which the real becomes an amusement park, a total screen.

Keywords: internet; interface; informational city; Disneyworld.

\section{Antes era o néon}

Apontam Asa Briggs e Peter Burke em Uma história social da mídia - De Gutenberg à Internet que "pode-se ver mais que um significado simbólico na mudança do vapor para a eletricidade durante as últimas décadas do século 19, pois eram as invenções elétricas que pareciam apontar mais claramente para o futuro" (2004, p. 190). A chegada da luz elétrica na segunda fase da Revolução Industrial (1850-1950) reconfigurou não apenas os sistemas de mídia e a paisagem e a infraestrutura urbanas, entre outros, mas a tornou principalmente um serviço de utilidade pública. 
Thomas Edison, inventor da lâmpada, imaginou que o seu dispositivo só seria vendável aos milhões se a eletricidade fosse levada até a casa das pessoas, o que, de fato, ocorreu. "Na história do vapor não consta desafio semelhante" (BRIGGS; BURKE, 2004, p. 191). Mas, na história da internet, a chamada rede mundial de computadores, pode-se afirmar que o desafio ultrapassa sobremaneira o efeito ocasionado pela eletricidade, mesmo tendo ainda alcance menor.

Diferentemente das consequências oriundas da eletricidade, o surgimento da internet, em 1969, revelou-se uma nova forma social que produziu novas práticas sociais, com possibilidades de ações específicas (ECHEVERRÍA, 1999; MANOVICH, 2001; CASTELLS, 2002). Essa alteração é notada desde o acesso a uma gigantesca base de dados, à ruptura da temporalidade e ao aumento exponencial de estratégias de vigilância, das sociedades disciplinares, organizadas em espaços de confinamento (FOUCAULT, 1997, p. 190214), que atingem seu apogeu no início do século 20, às atuais sociedades de controle, estruturadas ao ar livre (DELEUZE, 1992, p. 219-226), e às possibilidades de hackeamento da infraestrutura urbana (RATTI; CLAUDEL, 2016, p. 134), aperfeiçoadas com técnicas de Inteligência Artificial e tecnologias que estão cada vez mais invisíveis: "Elas se integram à vida do dia a dia, ao nosso cotidiano até serem indistinguíveis dele" (WEISER, 1991, p. 1).

É nesse contexto de consideráveis transformações culturais e tecnológicas que se forma a sociedade em rede, caracterizada pela fragmentação de sentido, originada de um sistema de comunicação hipertextual, pela emergência do tempo atemporal, com rupturas das sequências cronológicas (CASTELLS, 2011, p. 9), e pelo surgimento do espaço de fluxos, substituindo o espaço de lugares, que se opõe a, e isola, o local do global (CASTELLS, 1989, p. 348).

Conclui-se, assim, que a internet tem aplicação completamente diferente da eletricidade, embora dependa desta para operar. Integrada a essa sociedade está a cidade informacional: "não é uma forma, mas um processo, um processo caracterizado pelo patrimônio estrutural do espaço de fluxos" (CASTELLS, 2002, p. 488), principal base da sociedade em rede, fundamentada no conhecimento, com processos descentralizados e empresas organizadas pela economia informacional.

Portanto, é no informacionalismo que verifica-se tal mudança. Não só relacionada à tecnologia, à economia e à sociedade, mas também à paisagem urbana das cidades contemporâneas, com a introdução da media architecture (arquitetura de mídia), em meados dos anos 1980, e das media facades (fachadas de mídia), no início dos anos 1990. "A ideia de fachada de mídia transparente surgiu em 1992, mas para ter qualidade de imagem era preciso aperfeiçoamento da tecnologia LED (componente emissor de luz), o que levou o primeiro projeto dessa modalidade a ser realizado oitos anos depois" (MÜLLER, 2006, p. 6).

As media facades são definidas como "a incorporação de comunicação de uma fachada, principalmente na forma de mídia digital", e a media architecture tem como principal característica seu aspecto dinâmico: é a representação dinâmica de texto, gráfico, 
imagem ou vídeo, dentro ou fora de uma fachada (HAEUSLER, 2009, p. 12-14). Ou seja, é multimídia, como a televisão e a World Wide Web e aplicativos, e também contêm aspectos interativos. "A definição de media facades não inclui as fachadas com letreiros luminosos, com os de néon, nem as janelas de vidros das igrejas medievais, que já projetavam uma imagem iluminada através do sol, à semelhança de retroprojetores" (Ibidem, p. 21).

Graças à relação entre arquitetura, tecnologia e internet, as media facades remodelam a estética dos painéis luminosos, dominante até pelo menos 1999, que tornou-se marcante em cidades como Londres (Piccadilly Circus) ${ }^{1}$, Nova York (Times Square) ${ }^{2}$, Tóquio (Shibuya Crossing) 3 e Hong Kong (Causeway Bay) ${ }^{4}$. Na região da Times Square, no final da década de 1880, a eletricidade - na forma de anúncios em teatros, caso da Broadway, e iluminação pública - reordenou a paisagem urbana e trouxe mais segurança aos cidadãos ${ }^{5}$. Os primeiros passos para definir e classificar as media facades foram dados entre 2007 (Media Architecture London e Urban Screen Manchester) e 2008 (Urban Screen Melbourne e Media Facade Festival Berlin). Esse formato integrante da media architecture é dividido em cinco categorias - mecânica, eletrônica, projeção, iluminante e display.

Além da estética, essa reprogramação das fachadas estáticas luminosas para as media facades, percebida na passagem do século 20 para o 21, também leva a uma importante e urgente reflexão sobre questões legais. Há uma vasta legislação internacional sobre proteção da paisagem urbana, como a Carta de Atenas (1933), a Recomendação de Paris Unesco (1962; 1968; 2003), a Carta de Veneza (1964), Carta da Paisagem Mediterrânea, de Sevilha (1992), a Convenção Europeia da Paisagem, de Florença (2000) e a Recomendação sobre a Paisagem Histórica Urbana - Unesco (2011), entre outras. Paris, Berlim e Nova York têm legislação para fachadas. No Brasil, o exemplo mais significativo de reordenamento da paisagem é o da Lei Cidade Limpa, do município de São Paulo.

Posto assim, este artigo se propõe a debruçar-se sobre as projeções, também denominadas mapping ou video mapping, uma das categorizações das media facades, iniciadas no início dos anos 2000 na capital paulista, a partir da revisão da Lei Cidade Limpa. Esse recorte objetiva iniciar uma discussão a respeito de quais serão as implicações legais relacionadas a esse formato - sobretudo quando for possível que dispositivos móveis adquiram capacidade técnica (de imagem e de alcance) para reproduzir no espaço

1 De acordo com a Enciclopédia Britânica, os primeiros anúncios eletrônicos surgiram em 1910 em Piccadilly Circus. Já os outdoors são de 1923. Disponível em: <http://bit.ly/32Xq8A1>. Acesso em: 20 nov. 2019.

2 Considerada por Anthony Townsend um ambiente urbano digital, a Times Square teve seu primeiro grande painel eletrônico instalado em 1917. Em 1929, um painel, também eletrônico, foi usado para anunciar a vitória de Herbert Hoover à Presidência da República (1929-1933). In: HAEUSLER, 2009, p. 33.

3 O atual bairro Shibuya foi fundado em 1947. Para saber mais, ver: <http://bit.ly/339a0LV>. Acesso em: 20 nov. 2019.

4 De baía, no século XIX, o distrito de Causeway Bay começa a ter publicidade em sua paisagem no século XX, principalmente na década de 1980. Para saber mais, ver: <http://bit.ly/2XB3Hj0 > e <http://bit.ly/35nxA9g $>$. Acesso em: 20 nov. 2019.

5 Para saber mais, ver: <http://bit.ly/37h4KsZ>. Acesso em: 20 nov. 2019. 
informacional telas de projeções efêmeras (BEIGUELMAN, 2016, p. 38; 68) - e apresentar diretrizes gerais para uma proposição legal para a cultura digital.

O debate apresentado nas próximas páginas está ancorado no corte temporal que faz Matthias Hank Haeusler, professor de design da Escola Australiana de Arquitetura, em Media Facades - History, Technology, Content, publicado em 2009, para estudar a media architecture e as media facades. O ponto de partida de Haeusler é o momento em que arquitetos e designers consideraram, pela primeira vez, a aplicação de uma tela de tevê como componente de construção em um ambiente externo, como uma parede (p. 21). Estão, portanto, excluídos desse escopo os painéis eletrônicos, como os de néon.

Segundo esse critério, o projeto dos anos 1970 do Centro Pompidou, em Paris (França), vencedor entre mais de 680 outros e que contou com Oscar Niemeyer no júri, foi o primeiro a contemplar uma media facade. O desenho, que incluía na fachada principal uma tela gigante exibindo mensagens eletrônicas com notícias sobre cultura e política, antecipou as estéticas da Los Angeles futurista de Blade Runner, de Ridley Scott (1982), e as do arquiteto japonês Toyo Ito, em Yokohama, no Japão, com a Tower of winds (1986). Mas, por impedimentos técnicos, não foi levado adiante (PUGLISI, 1999, p. 5-10 e p. 18-21; HAEUSLER, 2009, p. 23-27). Esses projetos serão detalhados no próximo tópico.

Essa reflexão será ainda fundamentada a partir das noções de espaços lisos, sem fronteiras, estriado, delimitado (DELEUZE; GUATTARI, 2007, p. 180), e de Disneyworld (BAUDRILLARD, 2005, p. 122-124), na qual a ordem do mundo é disnéica, para além do imaginário, em que o real se torna um parque de atrações, uma tela total (Ibidem, p. 145-146).

\section{Agora as telas são efêmeras}

A discussão da relação entre tecnologia e arquitetura não é nova. Há trabalhos que contemplam essa simbiose desde os anos 1950. Yona Friedman e Constant Nieuwenhuys e integrantes do grupo inglês Archigram defendiam a ideia segundo a qual computadores conectados em redes poderiam mediar a interação entre pessoas e espaços (MCQUIRE, 2009). Em 1958, Friedman publica um manifesto intitulado Architecture Mobile, cuja proposição envolvia automação e mobilidade. É reflexo desse pensamento o Ville Spatiale (1958-1962), constituído por estruturas temporárias e leves, acima do solo, em cidades ou campos, criando uma paisagem a ser apropriada pelo cidadão ${ }^{6}$.

Projeto semelhante - modo de vida itinerante, móvel, interligado em rede -, começou a elaborar dois anos antes, em Alba (Itália), o artista holandês Constant Nieuwenhuys. Trata-se de New Babylon (1956-1969), um acampamento para nômades em uma escala planetária. O nome Babylon foi sugerido pelo escritor francês Guy Debord, amigo de longa data de Nieuwenhuys. O artista holandês incluiu o New à frente, em homenagem a New York, New Delhi e New Orleans.

6 Para saber mais sobre arquitetura e tecnologia, ver: <https://goo.gl/AfJVi7>. Acesso em: 20 nov. 2019. 
Dessa corrente de pensamento surge o grupo inglês Archigram ${ }^{7}$. Fundado em 1961 por arquitetos da Architecture Association, foi um dos mais importantes expoentes da abordagem urbana flexível e baseada em tecnologia. O grupo enxergou a arquitetura para além de estruturas estáticas. Embora utópicos, seus projetos apontavam possibilidades como o Plug-in-city (1964), uma megaestrutura que conectaria toda a Europa, em evolução constante, que incorpora residências, transporte e outros serviços essenciais. Reflexo da estética do incompleto, Plug-in-city não foi realizado. Com repertórios semelhantes, também integram o acervo The Walking City ou The Instant City ${ }^{8}$.

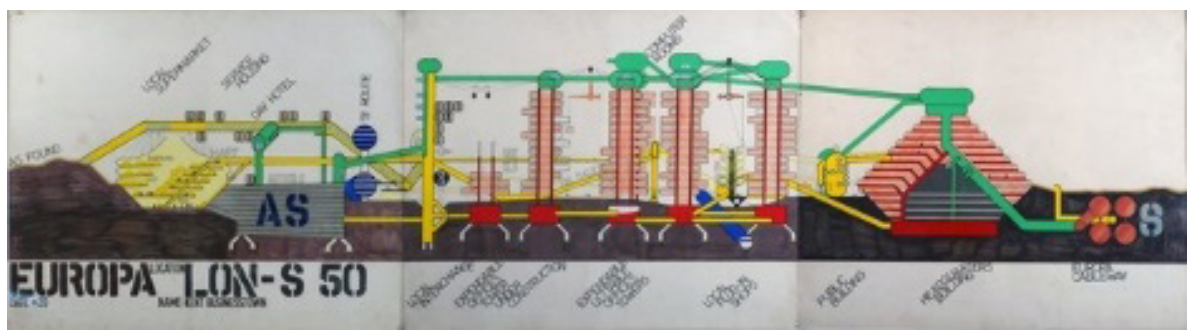

Fig. 1. Projeto Plug-in-City, desenhado pelo arquiteto Peter Cook. Crédito: Reprodução Archdaily.

A criação de ambientes dessa natureza levou o teórico Gordon Pask a desenvolver pesquisas pioneiras sobre cibernética em colaboração com integrantes também da Architecture Association, de Londres, do grupo Architecture Machine, do MIT (HAQUE, 2007). O cientista americano Nicholas Negroponte investigou a criação de ambientes para atender a necessidades de seus moradores. Já a integração de comandos de voz e gestos foi amplamente escrutinada em interfaces do Xerox Palo Alto Research Center (KALAY, 2004).

Esse potencial para desenvolvimento de projetos pensados em uma dinâmica de rede não refletia a falta de infraestrutura de conexão em um período pré-internet, portanto, antes de 1969. Quando a conexão em rede se tornou realidade, para além das esferas de governo, a partir da década de 1980, o interesse da computação na arquitetura se refletia em gráficos computacionais, animações, modelagens complexas, com o exemplo clássico do Museu Guggenheim, de Bilbao, de Frank Gehry (MCQUIRE, 2009).

Atualmente, nota-se que muitas propostas elaboradas são realidades em cidades contemporâneas, não restritas somente a construções, mas também a dispositivos móveis ou fixos, como, por exemplo, telas de tevê, sobretudo por consequência da Internet das Coisas. É nesse cenário que inserem-se a media architecture e as media facades. Embora a literatura de ficção e o cinema as tenham abordado, essas modalidades têm início, fora dessas esferas, nas décadas de 1970 e 1980, respectivamente, com o projeto do Centro Pompidou, já mencionado anteriormente (ver p. 5-6), e a Tower of winds, também já citada (ver p. 6) e destacada a seguir (ver p. 8).

7 Para saber mais sobre o grupo Archigram, ver: <https://goo.gl/CwSyCP>. Acesso em: 20 nov.2019.

8 Para saber mais sobre Plug-in-city, The Walking City ou The Instant City, ver: <https://goo.gl/dhRcbL >. Acesso em: 20 nov. 2019. 


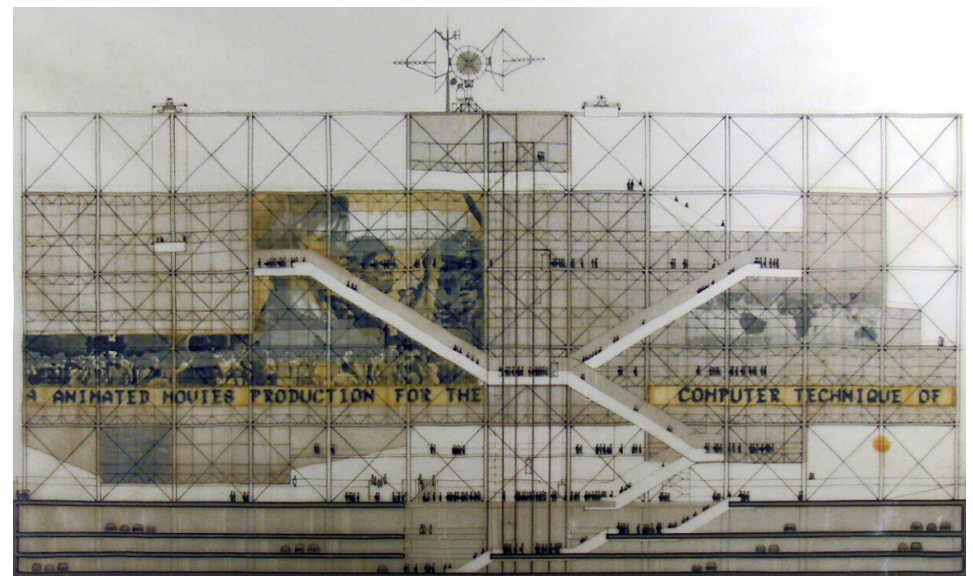

Fig. 2. Projeto do Centro Pompidou, considerado a primeira media facade. Crédito: Reprodução Archdaily.

Na literatura, o escritor Philip Kindred Dick é autor de variadas obras de ficção ${ }^{9}$ que abordaram e anteciparam estéticas tecnológicas hoje discutidas, e influenciou o diretor Ridley Scott no roteiro do clássico Blade Runner de $1982^{10}$. Foi baseado em Do Androids Dream of Electric Sheep? (Androides Sonham com Ovelhas Elétricas?), romance de ficção científica de Dick de 1968, que Scott introduziu as grandes telas nas fachadas da fictícia Los Angeles de novembro de 2019. No livro, o escritor de ficção científica entretinha os humanos com tevês em 3D. Com a inclusão das grandes telas no espaço urbano, o diretor de Blade Runner é considerado o precursor da media architecture (HAEUSLER, 2009, p. 23-24).

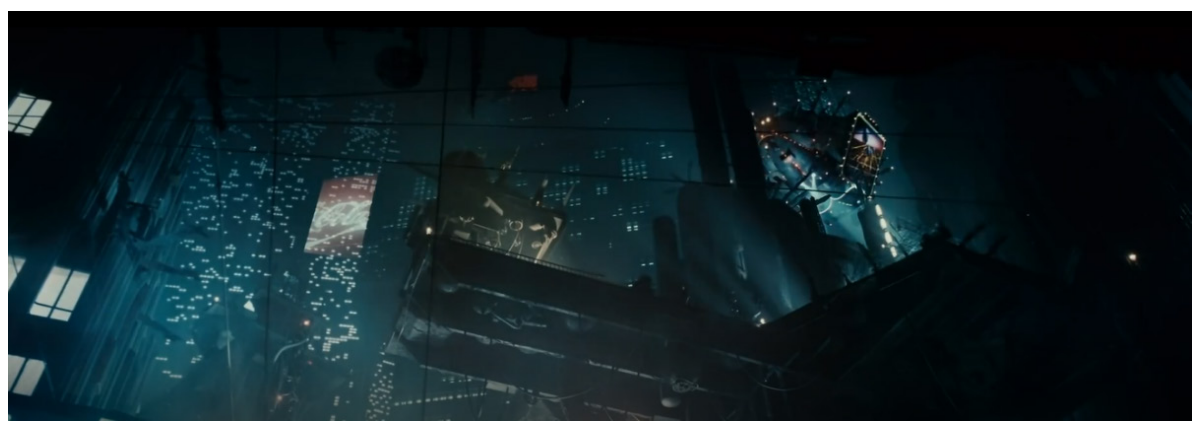

Fig.3. Telas gigantes exibidas em Blade Runner de 1982. Crédito: Reprodução.

9 Para saber mais sobre as obras de PKD, ver: <http://bit.ly/340m2bJ>. Acesso em: 20 nov. 2019.

10 Um breve resumo de Blade Runner: no século XXI, uma corporação desenvolve clones humanos para serem usados como escravos em colônias fora da Terra, identificados como replicantes. Em 2019, um ex-policial é acionado para caçar um grupo de fugitivos vivendo disfarçados em Los Angeles, nos Estados Unidos. 


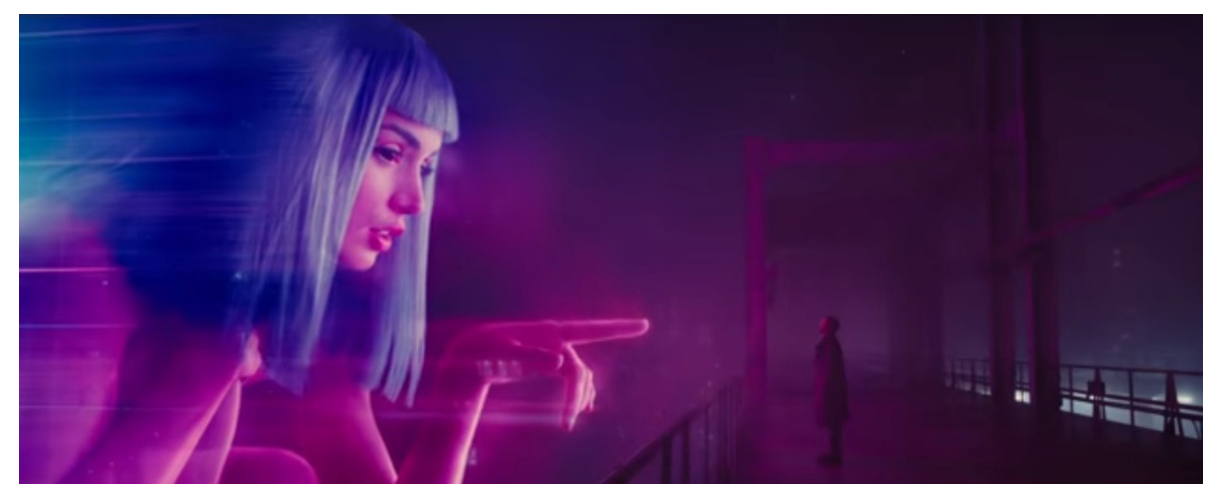

Fig.4. Holograma em Blade Runner 2049, de 2017. Crédito: Reprodução.

É preciso registrar, porém, que a estética de uma cidade flutuante, ladeada por placas luminosas de propaganda não começa em Do Androids Dream of Electric Sheep? e em Blade Runner, de 1982. A Metropolis, cidade-máquina da escritora Thea Von Harbou, em livro de mesmo nome, é ladeada por luzes coloridas de néon (1925, p. 35; 45). Embora mudo e em preto e branco, o filme, originário de sua obra e dirigido por seu então marido, o cineasta Fritz Lang, exibe a paisagem da cidade construída com blocos de luz ${ }^{11}$, e a organização de seu espaço urbano, como os veículos voadores e as vias que o circundam, está presente em Blade Runner. Fora das telas do cinema, outro precursor da media architecture é o arquiteto japonês Toyo Ito, com a obra Tower of winds (Torre dos Ventos), em Yokohama, no Japão, em 1986. A Tower of winds é controlada por computador e suas ações são programadas, explica o Archdaily (2012) ${ }^{12}$.
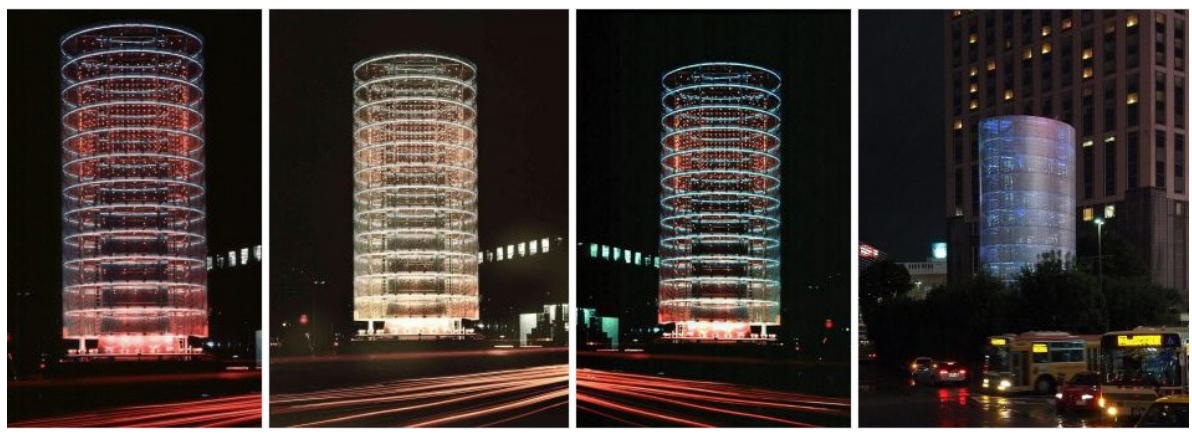

Fig. 5. Torre dos ventos, considerada precursora da media architecture. Crédito: Reprodução Archdaily.

No caso das media facades, a primeira grande fachada de mídia transparente do mundo foi instalada em 2003 na T-Mobile, empresa alemã de telefonia celular, com

11 A íntegra de Metropolis está disponível em: <http://bit.ly/2XMId2V>. Acesso em: 20 nov. 2019.

12 Para saber mais, ver: <http://bit.ly/2rOfvmb>. Acesso em: 20 nov. 2019. 
lâminas horizontais em uma superfície de 300 metros quadrados, dispostas na fachada de vidro. Os LED's integrados às lâminas permitiam uma encenação midiática da arquitetura, e os cidadãos podiam enviar imagens por meio de smartphones, com atualização em tempo real. Também as fachadas têm sido utilizadas para transmissão de eventos, como o Campeonato Mundial de Futebol de 2006. A competição foi exibida ao vivo pela fachada da Galeria Kaufhof, na Praça Alexanderplatz, em Berlim, com tamanho especificado pela norma urbanística do local (MÜLLER, 2006, p. 10; 77).

É importante anotar que a experimentação de técnicas de projeção não é recente, surgiu no século 18. O pioneiro dessa estética foi o mágico e ilusionista Étienne-Gaspard Robert em seus shows. Chamado de fantasmagoria, "é o resultado de uma condensação de várias experiências de ilusão de ótica, consistindo em montar uma lanterna mágica sobre trilhos para produzir personagens e figuras de tamanhos variados, projetados por fumaça" (MAX MILNER, 1982 apud PARENTE, 2016).

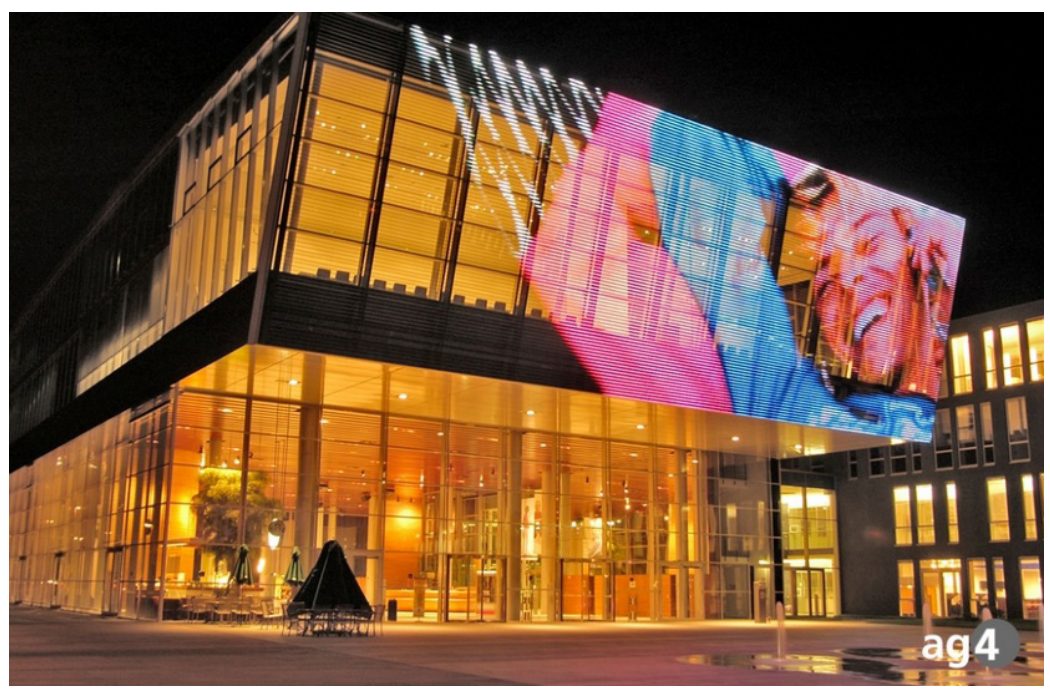

Fig. 6. Fachada transparente de LED da T-Mobile, em 2003, em Berlim. Crédito: Reprodução T-Mobile.

Modalidade das media facades, as projeções nos espaços urbanos têm início no mundo em 2000. Naquele ano, em Frankfurt, na Alemanha, um festival transdisciplinar, organizado na feira Light + Building, com o propósito de tornar a cidade, localizada à beira do rio Reno, em um amplo laboratório de abordagens com luz. Esse experimento deu origem, dois anos depois, a The Luminale-Biennial of Lighting Culture, contou Helmut Bien, curador e idealizador do evento, ao Media Architecture Institute ${ }^{13}$.

13 Para saber mais, ver: <http://bit.ly/334Mxvp>. Acesso em: 20 nov. 2019. 
Hoje essas telas urbanas, com projeções temporárias ou media facades dispostas por período indeterminado, entre outras estéticas, integram a paisagem na Ásia (Japão, China e Coreia do Sul), na Europa (além da Alemanha, Espanha, França, Holanda, Bélgica, Croácia, Inglaterra, Áustria e Polônia), Américas (Canadá, Estados Unidos, Peru e Brasil), Oceania (Austrália), África e Oriente Médio (Emirados Árabes, Líbia e Arábia Saudita), desde trabalhos de arte, ativismo e marketing (HAEUSLER; TOMITSCH; TSCHERTEU, 2012).

São essas novas configurações que extrapolam os espaços estriados, com fronteiras delimitadas (DELEUZE; GUATTARI, p. 180) de exibição de painéis - de eletrônicos a 3D -, como a Times Square, por exemplo, chamada de Disneyfied (ou "disneyficada"), consumível por toda a família, como em um parque comercial de entretenimento. A Disneyfication começou nos anos 1990, quando a companhia Disney abriu uma loja naquela cidade (HAEUSLER, 2009, p. 34-35). Ocorre, porém, que em um mundo cada vez mais intermediado por telas, a Disneylândia, característica da sociedade do espetáculo (DEBORD, 1997), foi substituída pela Disneyworld (BAUDRILLARD, 1997).
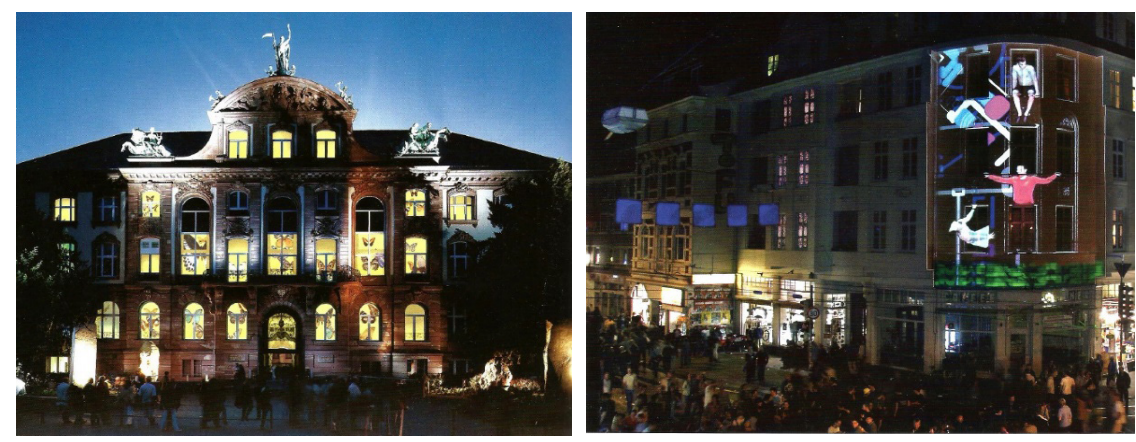

Fig. 7. Projeções em Frankfurt e Bremen (Alemanha) - 2004 e 2007. Crédito: Reprodução HAEUSLER, 2009).

É uma ordem "disnéica", inserida em uma lógica de tela total, na qual o real se torna o centro das atrações, um parque de diversões. "Não é mais o contágio do espetáculo que altera a realidade, mas a própria realidade é o espetáculo, e o sujeito não é mais espectador alienado e passivo, mas figurante interativo desse imenso reality show" (BAUDRILLARD, 1997, p. 122-124; 145-146). Nesse contexto, o mundo virou "uma performance interativa" (Ibidem).

Essa tela total é constituída no espaço de fluxos da cidade informacional, em que a computação e a internet são ubíquas, portanto sem mais dividir o mundo em digital e real, ou conectado e desconectado, "totalmente dependente das telecomunicações" para funcionar, o que Paul Virilio denominou cidade-mundo em O espaço crítico (2014). É nesse contexto que se dá a transformação do espaço público clássico no qual se redefine toda uma realidade coletiva, em um universo hi-tech de imediatez das imagens, escreveu o jornalista Paulo Roberto Pires ao apresentar o livro de Virilio. As projeções efêmeras são parte dessa reconfiguração. 
Mas é preciso, porém, registrar que, embora regradas por leis, normatizadas conforme determinação de cada governo local, as projeções efêmeras operam por meio de estratégias típicas de espaços lisos, sem fronteiras, nomádicos (DELEUZE \& GUATTARI, p. 180). Ou seja, há uma tensão constante em suas tratativas para ocupar o espaço urbano, que se manifesta no universo das leis. Por um lado, a Constituição, em seu artigo $5^{\circ}$, garante o livre pensar: "É livre a expressão da atividade intelectual, artística, científica e de comunicação, independentemente de censura ou licença"14. Por outro, o poder municipal regula desde períodos de exibição a conteúdos. Trata-se de um constante revezamento, em que "o espaço liso não deixa de ser constantemente convertido em espaço estriado, e o espaço estriado é constantemente revertido a um espaço liso. Há misturas e passagens de um para outro, graças a movimentos completamente diferentes" (Ibidem).

Essa tensão desafia os avanços tecnológicos. Embora seja razoável concordar que as "tecnologias não são planejadas, elas surgem conforme a cultura evolui" (KALAY, 2004, p. 475) e que "a realidade bastante diversa de nosso tempo caracteriza-se por um permanente estado de transição e, diante das exigências tecnológicas em transformação permanente, jamais chegará um momento em que finalmente as alcançaremos" (CRARY, 2016, p. 46-49), é preciso compreender que, do ponto de vista legislativo, é possível encontrar um equilíbrio nesse descompasso, como será proposto a seguir.

\section{Implicações legais}

Nesse contexto de estado permanente de transição está o aparelho celular, que há muito tempo perdeu sua função primeira de fazer e receber chamadas. Em Distrust that particular flavor (2012), William Gibson, um dos mais importantes estudiosos sobre a cultura da internet, escreveu: "A rua descobre seus próprios usos para as coisas - usos que nem o mercado imaginava" (p. 157). O autor do termo ciberespaço, nos anos 1980, se referiu às apropriações feitas de dispositivos que alteram suas funções originais.

O celular tornou-se um computador, habilitado para diversas funções, como reproduzir interfaces em superfícies externas, como MotoZ2 Play, da Motorola, e o Quantum V, da Positivo, o primeiro no Brasil com projetor a laser. Porém, ainda não é possível tecnicamente exibir tecnologias como holografia, Realidade Aumentada (RA) e Realidade Virtual (RV) para além do limite de sua tela, a exemplo de jogos (Pokémon GO) e trabalhos de arte (Jeff Koons e Sebastian Errazuriz).

Experimentos têm sido testados por empresas como Samsung (patenteou a tela holográfica em 2018), LG (anunciou uma grande tela dobrável no mesmo ano), Sony (apresentou dispositivo que rastreia movimentos gestuais em 2019), Qualcomm (anunciou um chip para facilitar a RA) e RED (fabricante de câmeras cinematográficas, estuda um celular para ser a primeira máquina holográfica de bolso do mundo). Já é possível, há pelo menos quatro anos, simular uma tela retroprojetora de hologramas por meio do uso de acetato ${ }^{15}$.

14 A íntegra do artigo $5^{\circ}$ da Constituição está disponível em: <http://bit.ly/37sXUAL>. Acesso em: 20 nov. 2019.

15 Para saber mais, ver: <http://bit.ly/2QUGOpw>. Acesso em: 20 nov. 2019. 


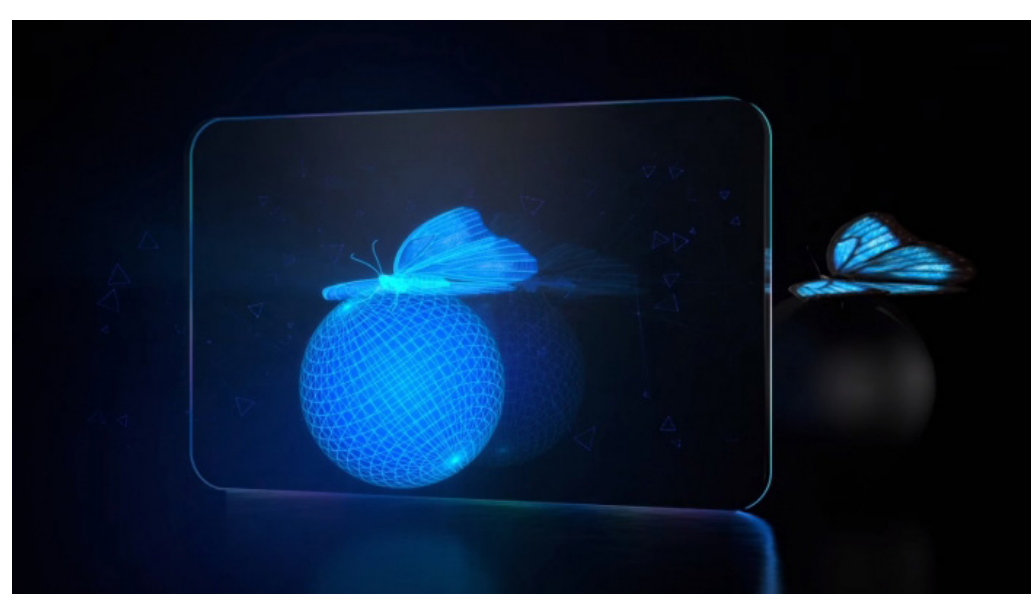

Fig. 8. Reprodução da RED de protótipo de smartphone que simula Realidade Aumentada.

A apropriação do smartphone como reprodutor de telas efêmeras é um exemplo a ser considerado no que se refere à elaboração de leis face aos avanços tecnológicos. Os testes para novas possibilidades de inserção de camadas de informação no espaço informacional indicam que não tardará a tornarem-se realidade. Ou seja, não se trata de uma tecnologia não planejada ou de uma transformação que não se pode alcançar. Tal exemplo é um alerta aos legisladores. Mas ocorre que os regramentos são elaborados sob demanda, não são planejados de forma a serem aplicados a inovações.

Com um recorte orientado para as projeções, uma das categorias das media facades, esse método foi verificado por esta pesquisadora em análise da Lei Cidade Limpa, aprovada no munícipio de São Paulo em 2006. Considerada exemplar, não só no Brasil, mas também no exterior, a lei tem o mérito de reordenar a paisagem urbana paulistana. Um inegável avanço. Mas é preciso ir além. O atual contexto exige uma reflexão acerca de sua atualidade.

Em vigor na capital desde 2007, a norma tem sido frequentemente complementada por resoluções, por não dar conta dos formatos originados mesmo antes de sua concepção, como as media facades. As projeções mapeadas ilustram essa dissonância. Em ações isoladas, essas modalidades começam a aparecer na paisagem urbana de São Paulo no fim dos anos 1990 e no início dos anos 2000: "Na calada da noite de domingo, apontava os equipamentos para os prédios vizinhos e observava os resultados", contou o VJ Alexis Anastasiou em Mappingfesto - Projection Mapping Manifesto (2007, p. 75).

As projeções começam a ter um planejamento para exibições em espaços públicos em $2004^{16}$, e o primeiro espetáculo foi realizado na capital em 2008, na fachada do Teatro Municipal (ANASTASIOU, 2017, p. 71; 76; 81), um ano após a Lei Cidade Limpa começar a valer. Outro evento de grande porte foi o Vídeo Guerrilha, em 2010. Essa, considerada

16 São Paulo não é a única localidade brasileira a ter eventos dessa natureza: Minas Gerais, Bahia, Rio de Janeiro, Brasília e Pará, entre outros, também recebem festivais com mapping. 
a primeira grande ação de mapping, começou em um prédio da rua Augusta, na região central, ocupado por sem-teto (Ibidem, p. 115).
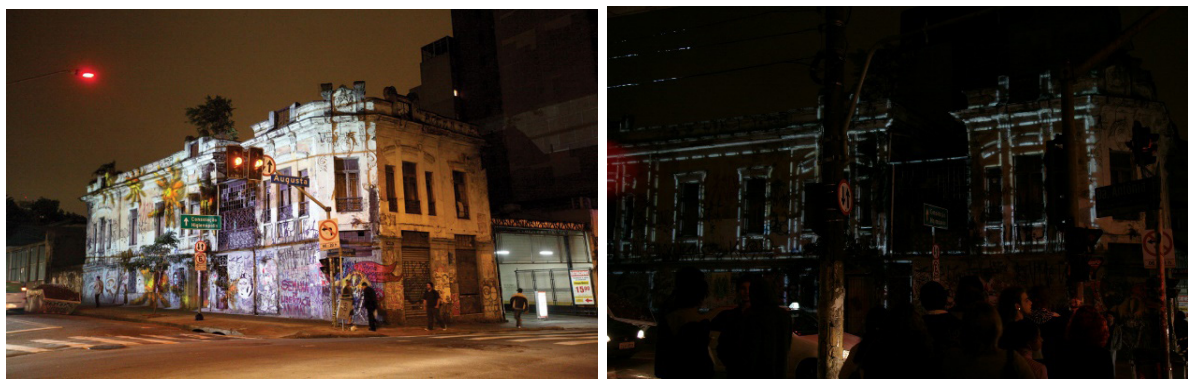

Fig. 9. Projeção em prédio da rua Augusta, em São Paulo, em 2010. Reprodução: Visualfarm.

Naquelas ocasiões, a regra não contemplava essa estética. Foi preciso anexar uma resolução, e a medida não foi redigida imediatamente. Sua publicação se deu em 2011, mais de uma década após o início dessas iniciativas. A resolução regulamenta especificamente as projeções temporárias (e conteúdos permitidos) de filmes, desenhos, fotos e imagens, em geral em fachadas de edifícios (públicos ou privados), monumentos, pontes, viadutos e demais construções permanentes ou temporárias. Quando visíveis do logradouro público, têm de ser previamente aprovadas pela Comissão de Proteção à Paisagem Urbana (CPPU), órgão ligado à Secretaria Municipal de Desenvolvimento Urbano ${ }^{17}$.

Esse é um dos casos em que foi necessário elaborar regramento específico para ser aplicado junto com a lei. Outra situação envolveu os painéis de LED dispostos em estabelecimentos comerciais na região central e na Avenida Paulista. Incomuns na época em que a lei foi pensada, o crescimento do uso desse tipo de propaganda motivou outra mudança ${ }^{18}$. "Em 2006, era muito caro, ninguém imaginava que iriam quebrar edifício para falar do próprio produto. Se espalhou, conforme foi barateando", afirmou Regina Monteiro, presidente da CPPU ${ }^{19}$.

Embora tenha sido retomada em 2005 pela Prefeitura, a discussão sobre a poluição visual em São Paulo tem origem na década de 1990 (SERVA, 2008, p. 16). Daquele momento em diante, houve muitas tentativas de reordenamento da paisagem urbana, com o objetivo de eliminar a poluição visual da cidade, porém sem incluir a media architecture ou as media facades em seu projeto final.

Por essa razão e com o intuito de dar início a uma discussão sobre sua a atualidade, como evitar que as resoluções se sobreponham à lei - há cerca de 50 -, esta pesquisadora entrevistou Ronaldo Lemos, advogado e especialista em cultura digital; Leão Serva, jornalista e autor do livro Cidade Limpa - O projeto que mudou a cara de São Paulo (2008);

\footnotetext{
17 A íntegra da Resolução sobre projeções está disponível em: <http://bit.ly/2QQCLKL>. Acesso em: 20 nov. 2019.

18 A íntegra da resolução sobre painéis eletrônicos está disponível em <http://bit.ly/2OK1Nc1>. Acesso em: 20 nov. 2019.

19 Para saber mais, ver: <https://bit.ly/2QjdEgZ>. Acesso em: 20 nov. 2019.
} 
Regina Monteiro, presidente da CPPU; Aloysio Nunes Ferreira, com larga experiência política - foi eleito deputado estadual pelo PMDB em 1982 -, então chefe da Casa Civil da Prefeitura durante a discussão e a aprovação da lei ${ }^{20}$; e a economista Ana Lobato, com mais de três décadas com atuação no Executivo e no Legislativo federais.

Está previsto no artigo 47 da Lei Cidade Limpa que "novas tecnologias e meios de veiculação de anúncios, bem como projetos diferenciados não previstos nesta lei, serão enquadrados e terão seus parâmetros estabelecidos pela Comissão de Proteção à Paisagem Urbana - CPPU". O artigo dá segurança à complementaridade da lei para o que não foi previsto à época de sua aprovação. Mas permite reeditar a lei praticamente sem limite algum.

Para dirimir essa ambiguidade, há duas soluções. Uma delas, proposta por Aloysio Nunes e por Ana Lobato é revisar a atual legislação, incluindo regras gerais de orientação e léxico. A norma atual remete a metáforas analógicas, não apenas em relação ao uso publicitário, mas também no que diz respeito ao vocabulário. Há, por exemplo, em seu texto mais de 40 variações do verbo instalar - projeções são exibidas, não são instaladas.

Na opinião da presidente da CPPU, Regina Monteiro, a Cidade Limpa tem instrumentos para atualizá-la: "O que estamos fazendo é uma avaliação de frases com dupla interpretação e verificando aquilo que realmente não precisa, que ficou arcaico. Falamos banner, por exemplo. Mas não há como regulamentar uma tecnologia que ainda não existe". Leão Serva defende que "a CPPU interprete os novos recursos tecnológicos à luz do espírito da lei. Em sua percepção, "não podemos criar novas leis para cada tecnologia que surge. Prefiro interpretar como adequar o direito existente às novas tecnologias".

A outra, proposta por Ronaldo Lemos, é elaborar uma lei geral de cultura digital que contemple o impacto das Tecnologias de Informação e da Comunicação no espaço urbano. Lemos alerta para a necessidade de refletir sobre a ocupação do espaço urbano: "Imagine quando tivermos drones voando - ou carros autônomos e outras modalidades que podem tornar a Cidade Limpa obsoleta?". E completa: "Além disso, as ferramentas de realidade aumentada podem tornar o espaço virtual da cidade completamente tomado por propaganda, inclusive mais nociva do que estamos acostumados".

Sendo assim, as contribuições anteriores levam à compreensão segundo a qual é coerente pensar em uma lei de cultura digital, orientada para as Tecnologias de Informação e de Comunicação do espaço urbano, com regras gerais e vocabulário não obsoleto. Além do que, o debate deste artigo indica a urgência de revisar as leis no país, não apenas a Cidade Limpa, mas a outras, como a que criminaliza hacker ou à que pune vazamentos de informações. Pois, se "as invenções elétricas pareciam apontar para o futuro", a rede aponta para o presente, como afirmou Lemos: "quem acha que a internet já provocou mudanças demais ainda não viu nada" ${ }^{21}$.

20 Para saber mais sobre a Lei Cidade Limpa, ver: <http://bit.ly/33v8GmZ>. Acesso em: 20 nov. 2019.

21 Para saber mais, ver: <http://bit.ly/37N6Dhm>. Acesso em: 20 nov. 2019. 
Luciana Moherdaui é pós-doutoranda na FAU-USP, onde pesquisa a influência das telas de projeções efêmeras nas cidades contemporâneas. Estuda os impactos da internet no jornalismo. É autora de Guia de Estilo Web, Produção e Edição de Notícias On-line, (SENAC, 2000; 2002; 2007) e Jornalismo sem manchete - A implosão da página estática (SENAC, 2016).

lucianamoherdaui@usp.br

\section{Referências}

ANASTASIOU, A. Mappingfesto: projection mapping manifesto. São Paulo: Visualfarm, 2017.

BAUDRILLARD, J. Tela total: mito-ironias da era do virtual e da imagem. Porto Alegre: Sulina, 1997.

BEIGUELMAN, G. Da cidade interativa às memórias corrompidas: arte, design e patrimônio histórico na cultura urbana contemporânea. 2016. Tese (Livre Docência em Linguagem e Poéticas Visuais) Faculdade de Arquitetura e Urbanismo, Universidade de São Paulo, São Paulo, 2016. Disponível em: <http://bit.ly/32FMIND>. Acesso em: 13 nov. 2019.

. "Arte pós-virtual: criação e agenciamento no tempo da Internet das Coisas e da próxima natureza". In: Cyber-arte-cultura: a trama das redes. Seminários Internacionais Museu Vale 2013, Vila Velha, 201. p. 147-171.

BRIGGS; BURKE. Uma história social da mídia: de Gutenberg à Internet. Rio de Janeiro: Jorge Zahar Editor, 2004.

CASTELLS, M. The informational city. Oxford: Blackwell Publishers, 1989.

A sociedade em rede. São Paulo: Paz e Terra, 2002.

. Museus na era da informação: conectores culturais de tempo e espaço. In: Revista Brasileira de Museus e Museologia, 2011, n. 5, p. 8-21. Brasília: Instituto Brasileiro de Museus, 2011.

CRARY, J. 24/7: capitalismo tardio e os fins do sono. São Paulo: Ubu, 2016.

DEBORD, G. A sociedade do espetáculo. Rio de Janeiro: Contraponto, 1997.

DELEUZE, G. Post-Scriptum sobre as sociedades de controle. In: Conversações: 1972-1990. Rio de Janeiro: Editora 34, 1992, p. 219-226.

DELEUZE, G.; GUATTARI, F. Mil Platôs - Capitalismo e esquizofrenia. São Paulo: Editora 34, v. 5, 2007.

ECHEVERRÍA, J. Los señores del aire: telépolis y el tercer entorno. Barcelona: Destino, 1999.

GIBSON, W. Neuromancer. São Paulo: Aleph, 2014.

Distrust that particular flavor. EUA: Penguin, 2012.

HAEUSLER, M. H; TOMITSCH, M; TSCHERTEU, G. New media facades: a global survey. Alemanha: Avedition, 2012.

HAEUSLER, M. H. Media facades: history, technology, content. Alemanha: Avedition, 2009.

KALAY, Y. E. Architecture's new media: principles, theories, and methods of computer-aided design. EUA: MIT, 2004.

MANOVICH, L. The language of new media. Cambridge: MIT, 2001. 
MCQUIRE, S. Mobility, cosmopolitanism and Public space in the media city. In: Urban Screens Reader. Amsterdam: Institute of Network Cultures, 2009.

MITCHELL, W. J. City bits: space, place, and the infobahn. Cambridge/MA: MIT Press, 1996.

MÜLLER, R. et al. AG4 media facades. Cologne: DAAB, 2006.

PARENTE, A. Do quase ao pós-cinema: o cinema como efeito. In: SANTAELLA, L. (Org.). Novas formas do audiovisual. São Paulo: 2006.

PUGLISI, P. L. Hyper Architecture: spaces in the electronic age. Suíça: Birkhauser, 1999.

RATTI, C; CLAUDEL, M. The city of tomorrow: sensors, networks, hackers and the future of urban life. EUA: Yale University Press, 2016.

SANTOS, R. E. A iluminação pública como elemento da paisagem urbana. 2005. 109 f. Dissertação (Mestrado em Arquitetura) - Faculdade de Arquitetura, Universidade Federal do Rio Grande do Sul, Curitiba, 2005.

SERVA, L. Cidade Limpa: o projeto que mudou a cara de São Paulo. São Paulo: Clio, 2008.

VIRILIO, P. Espaço crítico. São Paulo: Editora 34, 2014.

WEISER, M. The computer for the 21st century. Scientific american, vol. 265, no. 3, pp. 94-104, 1991. 